\title{
On the decadal increase in the tropical mean outgoing longwave radiation for the period 1984-2000
}

\author{
D. Hatzidimitriou ${ }^{1,2}$, I. Vardavas ${ }^{1,2}$, K. G. Pavlakis ${ }^{2}$, N. Hatzianastassiou ${ }^{2,3}$, C. Matsoukas ${ }^{2}$, and E. Drakakis Ma $^{2,4}$ \\ ${ }^{1}$ Department of Physics, University of Crete, Heraklion, Crete, Greece \\ ${ }^{2}$ Foundation for Research and Technology-Hellas, Heraklion, Crete, Greece \\ ${ }^{3}$ Department of Physics, University of Ioannina, Greece \\ ${ }^{4}$ Department of Electrical Engineering, Technological Educational Institute of Crete, Greece
}

Received: 10 February 2004 - Published in Atmos. Chem. Phys. Discuss.: 17 May 2004

Revised: 23 July 2004 - Accepted: 18 August 2004 - Published: 27 August 2004

\begin{abstract}
In the present paper, we have calculated the outgoing longwave radiation at the top of the atmosphere (OLR at TOA) using a deterministic radiation transfer model, cloud data from ISCCP-D, and atmospheric temperature and humidity data from NCEP/NCAR reanalysis, for the seventeenyear period 1984-2000. We constructed anomaly time-series of the OLR at TOA, as well as of all of the key input climatological data, averaged in the tropical region between $20^{\circ} \mathrm{N}$ and $20^{\circ} \mathrm{S}$. We compared the anomaly time-series of the model calculated OLR at TOA with that obtained from the ERBE S-10N (WFOV NF edition 2) non-scanner measurements. The model results display very similar seasonal and inter-annual variability as the ERBS data, and indicate a decadal increase of OLR at TOA of $1.9 \pm 0.2 \mathrm{Wm}^{-2} /$ decade, which is lower than that displayed by the ERBS time-series $\left(3.5 \pm 0.3 \mathrm{Wm}^{-2}\right)$. Analysis of the inter-annual and long-term variability of the various parameters determining the OLR at TOA, showed that the most important contribution to the observed trend comes from a decrease in high-level cloud cover over the period 1984-2000, followed by an apparent drying of the upper troposphere and a decrease in low-level cloudiness. Opposite but small trends are introduced by a decrease in low-level cloud top pressure, an apparent cooling of the lower stratosphere (at the $50 \mathrm{mbar}$ level) and a small decadal increase in mid-level cloud cover.
\end{abstract}

\section{Introduction}

Recent analysis of satellite broadband observations (ERBS WFOV, ERBE/ERBS scanner, ScaRaB, CERES) of the outgoing longwave (thermal infrared) radiation (OLR) at the top of the atmosphere (TOA) over the period 1979-2001 indi-

Correspondence to: I. Vardavas

(vardavas@iesl.forth.gr) cates that in the tropical region there has been a significant increase in the OLR at TOA by about $2.8 \mathrm{Wm}^{-2} /$ decade $^{1}$ (Chen et al., 2002; Wielicki et al., 2002a, b). Most of this occurred from the late 1980s to the mid to late 1990s and appears to be related to a decrease in total cloudiness (as given by ISCCP) for the same period over the tropics. Wang et al. (2002) used a simple parameterisation for the cloud longwave radiative forcing, along with cloud vertical distributions derived from SAGE II solar occultation measurements, to conclude that about $40 \%$ of the observed OLR trend for the years 1985-1998 can be accounted for by changes in the cloud vertical distribution, while they suggested that a change in cloud effective emissivity (i.e. the product of cloud fraction and emissivity) could account for the remainder of the OLR changes. Chen et al. (2002) found that the observed flux changes are associated with a decadal-time-scale strengthening of the tropical Hadley and Walker circulations. Trenberth (2002), however, challenged the reality of the OLR trend, because of the great difficulty of deriving reliable flux time-series from space, when there is no overlap between satellite records. Observations from narrowband scanning radiometers (AVHRR and HIRS) have been used (Wielicki et al., 2002a, data supplement http://www.sciencemag.org/cgi/ content/full/295/5556/841/DC1) to derive broadband longwave radiative fluxes: AVHRR OLR fluxes showed a decrease of $2 \mathrm{Wm}^{-2} /$ decade in the tropical region, for the period 1985-2000, while HIRS OLR data showed an increase of about $1 \mathrm{Wm}^{-2} /$ decade for the same period. In the recent reprocessing of AVHRR data, which resulted in the PATMOS climate dataset, Jacobowitz et al. (2003) examined the time-series of the OLR at TOA, in the tropics $\left(20^{\circ} \mathrm{N}-\right.$ $20^{\circ} \mathrm{S}$ ), for the period from September 1981 through to December 1999. They found that the OLR decreased by a little less than $2 \mathrm{Wm}^{-2}$ for the period from 1985 to 2000 .

\footnotetext{
${ }^{1}$ This is the revised value given by Wielicki et al., $2002 \mathrm{~b}$.
} 
Model 1985-1989 Annual Average

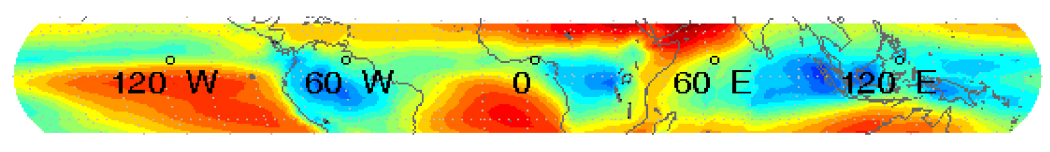

ERBE 1985-1989 Annual Average

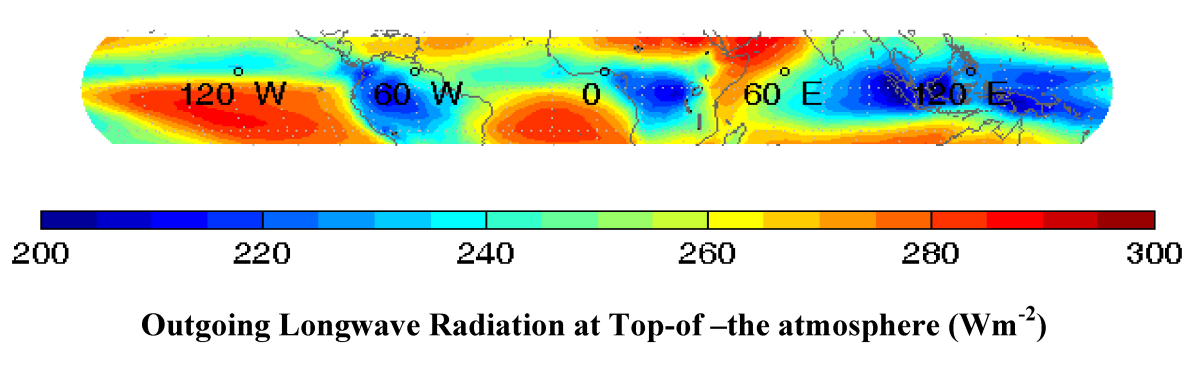

Fig. 1. The upper panel shows the geographical distribution of the outgoing longwave radiation at the top of the atmosphere as calculated by the model, while the lower panel as given by ERBE. Both maps give the annual long-term average calculated over the 52-month period covered by the ERBE dataset (1985-1989).

However, this decrease was caused mainly by larger values of the OLR from 1985 to 1988, compared to the rest of the values from 1988 to 2000 . They conclude that, on the whole, there was no consistent trend throughout the 18-year period. Finally, it is also noteworthy that General Circulation Models, studied by Wielicki et al. (2002a) and Allan and Slingo (2002), failed to show any long-term trend of the OLR at TOA.

In the present paper, we have calculated the OLR at TOA using a deterministic radiation transfer model, cloud data from ISCCP-D, and atmospheric temperature and humidity data from NCEP/NCAR reanalysis, for the period 19842000. We then constructed anomaly time-series of the OLR at TOA, as well as of all of the key input climatological data, averaged in the tropical region between $20^{\circ} \mathrm{N}$ and $20^{\circ} \mathrm{S}$. We compared the anomaly time-series of the OLR at TOA with that obtained from the ERBS S-10N (edition 2) measurements. We then examined the effect of any long-term changes detected in the time-series of the input data, to changes of the OLR at TOA.

\section{Model description and input data}

The LW fluxes at TOA and at the Earth's surface were computed using the FORTH longwave radiative transfer model, which is based on a detailed radiative-convective model (Vardavas and Carver, 1984). The model has been successfully tested (cf. Hatzianastassiou et al., 1999; Hatzianastassiou and Vardavas, 2001) according to the Inter-comparison of Radiation Codes in Climate Models (ICRCCM) program. The same model was also used to calculate the downwelling longwave fluxes at the surface in Pavlakis et al. (2004).
Monthly fluxes were derived on a $2.5^{\circ}$ resolution, for the tropical region, between $20^{\circ} \mathrm{N}$ and $20^{\circ} \mathrm{S}$. We used simple expressions for the total absorption of infrared radiation by the atmospheric molecules, independently in each $2.5^{\circ} \times 2.5^{\circ}$ pixel, dividing vertically the atmosphere (from the surface up to $50 \mathrm{mb}$ ) in about $5 \mathrm{mb}$ layers to ensure that they are optically thin with respect to the Planck mean longwave opacity, and using simple transmission coefficients which depend on the amount of absorbing molecules in each layer. The molecules considered are; $\mathrm{H}_{2} \mathrm{O}, \mathrm{CO}_{2}, \mathrm{CH}_{4}, \mathrm{O}_{3}$, and $\mathrm{N}_{2} \mathrm{O}$. The sky is divided into clear and cloudy fractions. The cloudy fraction includes three non-overlapping layers of low, mid and high-level clouds ${ }^{2}$. Expressions for the fluxes for clear and cloudy sky can be found in Hatzianastassiou et al. (1999). All of the cloud climatological data are taken from the ISCCP-D2 data set (Rossow and Schiffer, 1999), which supplies monthly means for 72 climatological variables in $2.5^{\circ}$ equal-angle pixels for the period 1984-2000. For the total amount of ozone, carbon dioxide, methane, and nitrous oxide, we used the same values as in Hatzianastassiou and Vardavas (2001).

The vertical distributions of the temperature and water vapor are taken from the NCEP/NCAR reanalysis (Kistler et al., 2001), corrected for topography as in Hatzianastassiou et al. (2001).

\footnotetext{
${ }^{2}$ Quantification of the cloud overlap effect on the OLF is a difficult problem. However, for example, based on the maximum overlap scheme without conservation of the optical depth, described in Chen et al (2000), we estimate that the observed trend in the OLF, would be increased by up to $0.2 \mathrm{Wm}^{-2} /$ decade. On the other hand, assuming conservation of the optical depth with maximum overlap, there is an equivalent decrease in the OLF trend.
} 


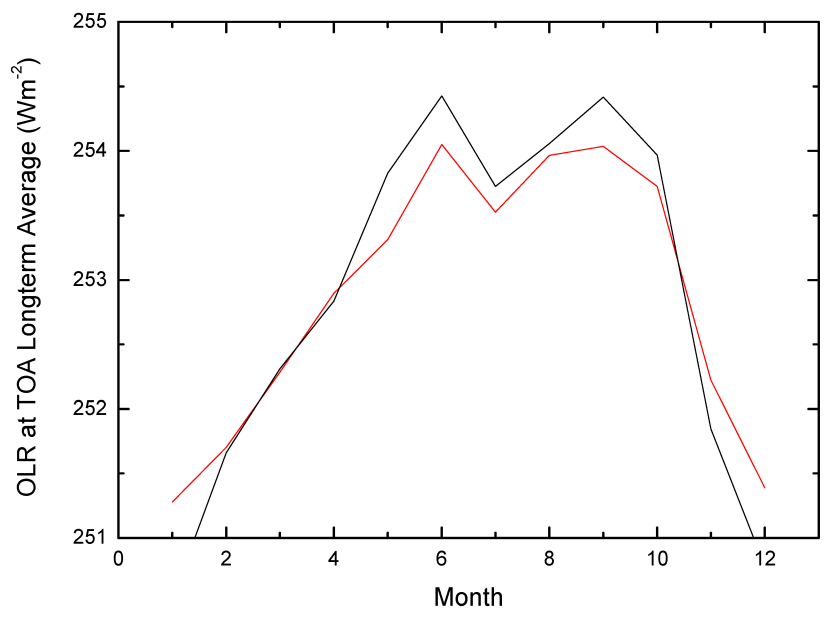

Fig. 2. Average seasonal cycle displayed by the model OLR (black line) and the ERBE OLR (red line), after having subtracted from the model data the value of $4.6 \mathrm{Wm}^{-2}$ (model bias).

Above the $300 \mathrm{mb}$ level, NCEP/NCAR does not provide water vapor data, thus we have used a typical specific humidity at $50 \mathrm{mb}$ based on HALOE measurements at that level. HALOE data do not cover the entire period studied here. We have, thus, adopted the same average value for all years; this point is further discussed later.

\section{Model validation}

The model calculated outgoing fluxes at the top of the atmosphere were validated against ERBE (Earth Radiation Budget Experiment) scanner fluxes, for the years 19851989 (for which ERBE data are available), for all $2.5^{\circ}$ gridboxes within the $20^{\circ} \mathrm{N}-20^{\circ} \mathrm{S}$ zone. The correlation coefficient between model calculated and ERBE fluxes is $\mathrm{R}=0.96$. The average difference between model and ERBE fluxes is $4.6 \pm 0.1 \mathrm{Wm}^{-2}$, with a standard deviation of $6.3 \mathrm{Wm}^{-2}$, with the model fluxes being higher on average than the ERBE fluxes. Figure 1 shows the geographical distribution of the long-term annual average of the longwave outgoing flux at the top of the atmosphere as calculated by the model (upper panel) and as given by ERBE (lower panel). The agreement is generally very good, with differences less than $5 \%$ on a pixel level over most of the area studied. The average seasonal cycle displayed by the model fluxes for the tropical zone is also in excellent agreement with the seasonal variability displayed by the ERBE data, as can be seen in Fig. 2 . A full analysis of the model results both regionally and globally, using different reanalysis input data for the temperature and humidity profiles (along the lines of the study of Pavlakis et al., 2004, for the downwelling longwave flux) are beyond the scope of the present paper and will be the subject of a future paper.

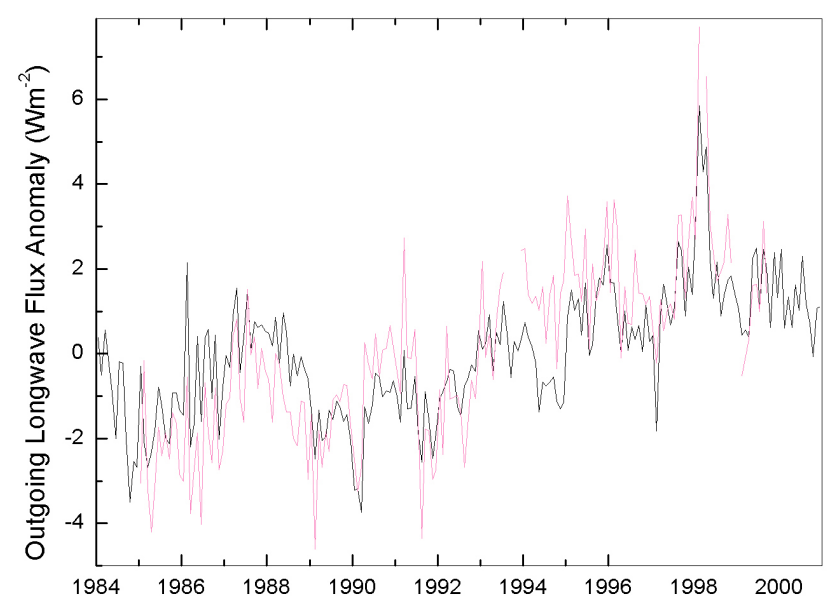

Fig. 3. Time-series of the tropical $\left(20^{\circ} \mathrm{N}-20^{\circ} \mathrm{S}\right)$ mean outgoing longwave radiation anomaly at the top of the atmosphere for the period 1984-2000, as derived by the model (black line), using ISCCPD2 cloud data and NCEP/NCAR Reanalysis data. For comparison, the red line shows the ERBE S-10N (WFOV NF edition 2) nonscanner measurements for the same zone and for the period 19851999.

\section{OLR anomaly time-series}

Figure 3 (black line) shows the time-series of the anomaly of the mean monthly longwave outgoing flux at the top of the atmosphere with respect to the $1985-1989^{3}$ average monthly fluxes (from which the average seasonal cycle has been removed), for the tropical region (between $20^{\circ} \mathrm{N}$ and $20^{\circ} \mathrm{S}$ ) and for the period 1984-2000 for which ISCCP-D2 data are available. For comparison we have overlaid on the same diagram the tropical mean anomaly shown by the ERBE S$10 \mathrm{~N}$ (WFOV NF edition 2) non-scanner data (red line). The agreement between the two time-series is remarkable. Linear regression between the model and satellite data yielded a correlation coefficient of $\mathrm{R}=0.84$. Both time-series display very similar inter-annual variability. They both show a broad maximum in 1987, concurrent with the 1986/1987 El Niño event, followed by a minimum in 1990, corresponding to the 1989/1990 La Niña. A strong peak appears in 1998, corresponding to the El Niño of 1997/1998. The longterm behavior of the two time-series is also quite similar. They both show a decadal increase, but of different magnitude. The model calculated OLR time-series yields a formal decadal increase of $1.9 \pm 0.2 \mathrm{Wm}^{-2}$ for the period 1984 2000, while the ERBS time-series gives a formal decadal increase of $3.5 \pm 0.3 \mathrm{Wm}^{-2}$, which is in broad agreement with the Wielicki et al. (2002a) result ${ }^{4}$. Therefore, although the

\footnotetext{
${ }^{3}$ In agreement with the choice of Wielicki et al. (2002) for the reference period used for the construction of the anomaly time series.

${ }^{4}$ The decadal increase found here for the ERBS dataset is in agreement with the original Wielicki et al. (2002a) result. Wielicki
} 


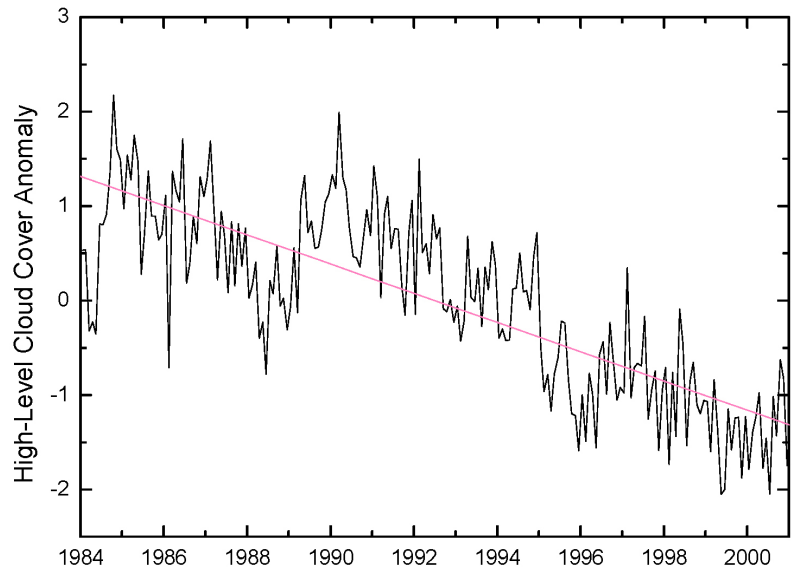

(a)

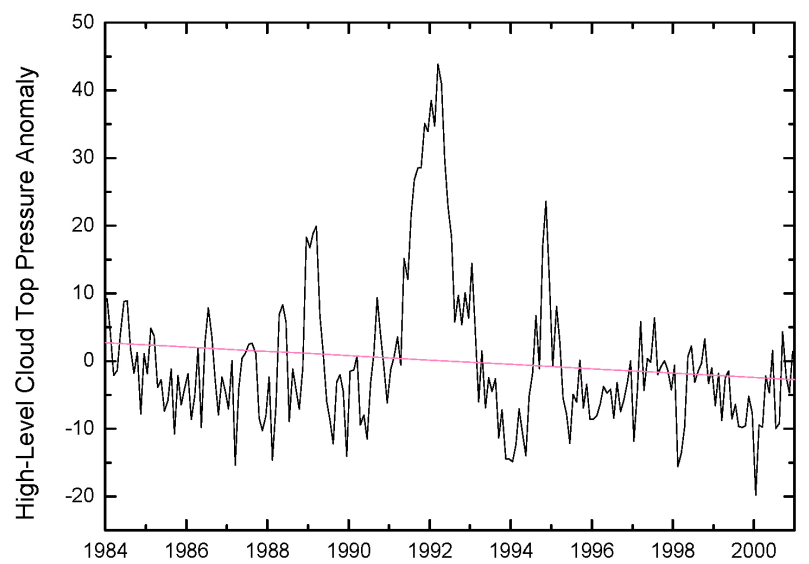

(b)

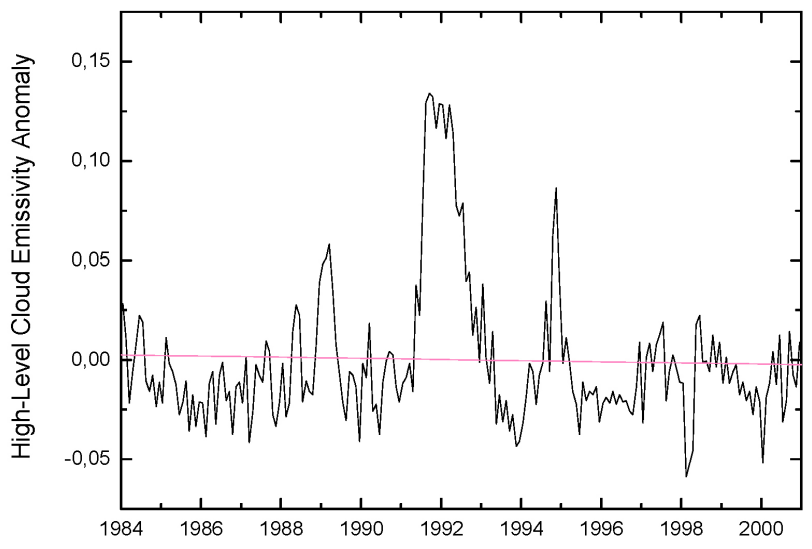

(c)

Fig. 4. (a) Time-series of the tropical mean high-level cloudiness anomaly (absolute percent) for the period 1984-2000. (b) Timeseries of the anomaly of the high-level cloud top pressure (mbar) for the period 1984-2000. A significant peak is observed following the Pinatubo eruption (June 1991). (c) Time-series of the anomaly of the high-level cloud emissivity for the period 1984-2000. A significant peak is observed following the Pinatubo eruption (June 1991).

et al. (2002b) revised their estimate to $2.8 \mathrm{Wm}^{-2}$ by introducing a correction to the ERBS data. This new estimate is still significantly model calculated fluxes show excellent agreement with the ERBS data as far as short-term inter-annual variability is concerned, the long term positive trend of the model OLR is lower than the ERBS (or the Wielicki et al., 2002a) value.

\section{Climatological data anomaly time-series}

We have explored the long-term variability behaviour of all of the main climatological parameters used as input to our model (described in Sect. 2) and attempted to determine which of these parameters contribute significantly to the observed OLR trend (as calculated by our model), for the period 1984-2000. The methodology used is simple: we constructed the anomaly time-series for each input parameter, in exactly the same way as the OLR anomaly time-series was constructed. Whenever a statistically significant decadal decrease or increase was observed, we introduced this change for the particular parameter in the model, recalculated the OLR at TOA, and derived the induced change (in $\mathrm{Wm}^{-2}$ ). Table 1 summarizes the results of this analysis. Column 1 gives the list of input parameters, column 2 gives the actual decadal increase, or decrease, found, along with the statistical error, and column 3 the induced change in the OLR at TOA. In the following paragraphs we discuss the results separately for (i) the cloud parameters, (ii) the atmospheric temperature profile and (iii) precipitable water in different atmospheric layers. It should be emphasized here that the individual radiative forcings of the different changes that appear in the following paragraphs and in Table 1 should not be added in a simple fashion, as the climate system is highly non-linear. They only provide a means of ranking the various factors causing the observed variability of the OLR at TOA.

\subsection{Cloud properties}

High-level clouds: A uniform long-term decrease of highlevel cloudiness seems to have occurred over the tropics (from $20^{\circ} \mathrm{S}$ to $20^{\circ} \mathrm{N}$ ) during the period 1984-2000, at least according to the ISCCP-D record, which is used in the present study. According to the anomaly time-series shown in Fig. 4a, the high-level cloud amount decreased significantly, at a rate of about $-10.1 \pm 0.5 \%{ }^{5}$ (relative, not absolute, decrease) per decade, resulting in an increase of the OLR at TOA of about $1.5 \mathrm{Wm}^{-2}$ (Table 1 ).

Anomaly time-series for the high-level cloud top pressure and emissivity have also been constructed (Figs. 4b and c). The high-level cloud top pressure shows no overall significant decrease, or increase in the period studied. However, it did increase significantly, by about 50 mbar, in mid-1991 (after the Pinatubo eruption) and returned to the pre-Pinatubo

higher than the model calculated increase, found here.

${ }^{5}$ Percent difference is with respect to the 17-year average, i.e. (calculated percent difference $)=100 *$ (cloud cover decadal change)/(mean cloud cover over 17 year period). 
Table 1.

\begin{tabular}{llc}
\hline Parameter & Decadal trend & Outgoing longwave radiative forcing at $\mathrm{TOA}^{\left(\mathrm{Wm}^{-2}\right)}$ \\
\hline Low-level cloud amount & $-6.5 \pm 0.4 \%^{*}$ & $0.23 \uparrow$ \\
Mid-level cloud amount & $1.6 \pm 0.4 \% \%^{*}$ & $0.1 \downarrow$ \\
High-level cloud amount & $-10.1 \pm 0.5 \%^{*}$ & $1.5 \pm 0.1 \uparrow$ \\
Low-level cloud top pressure & $-1.8 \pm 0.2 \%^{*}$ & $0.34 \downarrow$ \\
Atmospheric temperature at 50 $\mathrm{hP}(\mathrm{K})$ & $-0.9 \pm 0.2 \mathrm{~K}$ & $0.2 \downarrow$ \\
Precipitable water 500-300 $\mathrm{hP}\left(\mathrm{g} \mathrm{cm}^{-2}\right)$ & $-3.1 \pm 0.6 \% *$ & $0.53 \uparrow$ \\
\hline
\end{tabular}

* Relative change

values by the end of 1992 (Fig. 4b). At the same time, the high-level cloud emissivity increased by about $30 \%$ (relative increase), returning to the pre-Pinatubo average by the end of 1992 (Fig. 4c). No significant overall trend was observed. The peak in high-level cloud top pressure and the peak in cloud emissivity introduce OLR changes of opposite sign, which almost cancel out. This explains why the OLR shows no similarly strong peak around 1992 (Fig. 3).

Mid-level clouds: Contrary to the high and low-level cloudiness which appear to have decreased over the past couple of decades, according to the ISCCP record, mid-level cloud amount shows a small decadal increase of $1.6 \pm 0.4 \%$ (relative increase). This increase by itself would cause a small decrease of the OLF at TOA (of about $0.1 \mathrm{Wm}^{-2}$ ). Mid-level cloud top pressure and emissivity show no significant long-term change.

Low-level clouds: Low-level cloud amount decreased during the period 1984-2000, at a rate of about $-6.5 \pm 0.4 \%^{5}$ (relative decrease) per decade, which would result (by itself) in an increase of the OLR at TOA of about $0.2 \mathrm{Wm}^{-2}$ per decade (Table 1). At the same time there has been a decadal decrease of the low-level cloud top pressure by about $-1.8 \pm 0.2 \%$ (relative decrease), which would introduce a small decadal decrease of the OLF at TOA, of about $-0.3 \mathrm{Wm}^{-2} /$ decade, which almost cancels out the effect of the decrease in low-level cloudiness. So, on the whole, lowlevel clouds seem to have almost a zero contribution in the observed OLF trend.

The overall trend in OLR introduced directly by changes in all cloud properties together is about $70 \%$ of the overall trend in the model calculated OLR and it is mainly due to the highlevel cloud cover decrease. Wang et al. (2002) suggested that part of the observed trend in the OLR could be attributed to reduced mean cloud opacity. However, we have found no significant trend in cloud emissivity that could contribute to the overall trend in OLR, at least according to the ISCCP record.

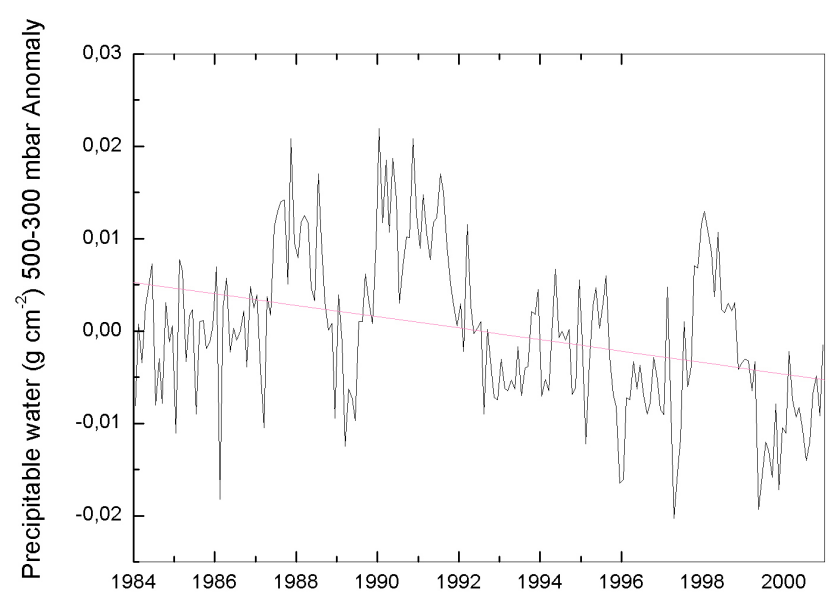

Fig. 5. Time-series of the upper tropospheric water vapour (500300 mbar) anomaly for the period 1984-2000.

\subsection{Precipitable water}

NCEP/NCAR water profiles are only available up to 300 mbar. Time-series of precipitable water in three layers (surface to $700 \mathrm{mbar}, 700-500 \mathrm{mbar}$ and above $500 \mathrm{mbar}$ ) were constructed. A non-monotonic decrease of precipitable water in the upper troposphere (above $500 \mathrm{mbar}$ ), amounting to $-3.1 \pm 0.6 \%$ per decade, is exhibited by the NCEP/NCAR data (Fig. 5). This trend introduces (by itself) an increase of the OLR at TOA of $0.53 \mathrm{Wm}^{-2} /$ decade. However, it must be noted here that this drying of the upper troposphere, which is also found in TOVS statistical retrievals (Schroeder and McGuirk, 1998), is not supported by either microwave or TOVS-physical retrievals (Soden and Schroeder, 2000). Bates and Jackson (2001), based on 20-year HIRS data, actually find a positive trend for the upper tropospheric water vapor in the deep tropics, definitely not shown by the NCEP data used here. It is clear, therefore, that estimated trends in upper tropospheric humidity remain ambiguous.

Another important issue is atmospheric humidity above 300 mbar. In our model calculation, we assumed a fixed value of the specific humidity at $50 \mathrm{mbar}$, as explained in 


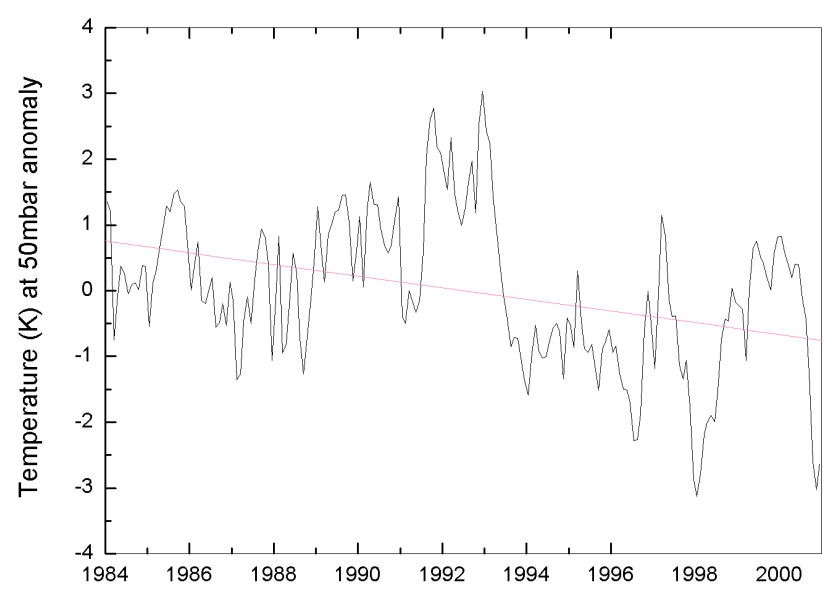

Fig. 6. Time-series of the atmospheric temperature anomaly at 50 mbar for the period 1984-2000.

Sect. 2. It is possible that the fact that we find a much lower decadal increase of the OLR at TOA than shown by the ERBS data, could be due to this assumption. If there was a decrease, for example, of $10 \%$ per decade, for the specific humidity at $50 \mathrm{mbar}$ (see e.g. IPCC, 2001; Kley et al., 2000), this would - by itself - cause an increase of the OLR at TOA of about $0.25 \mathrm{Wm}^{-2}$ per decade.

\subsection{Atmospheric temperature profiles}

Time-series of the atmospheric temperature (from NCEP/NCAR reanalysis) at various atmospheric levels were constructed. No significant decadal trends were found for the air temperature at any atmospheric level (see also Kistler et al., 2001), other than in the lower stratosphere where there appears to be a decadal decrease of $0.9 \pm 0.2 \mathrm{~K} /$ decade (Fig. 6). This decrease is non-monotonic, caused by a drop of about $1.3 \mathrm{~K}$ around 1993 . Note that IPCC 2001 gives a decrease for the period 1979-2000 ranging from $0.3-0.7 \mathrm{~K} / \mathrm{decade}$. The effect on the OLR at TOA of this $(0.9 \mathrm{~K} /$ decade $)$ trend is of the order of $-0.23 \mathrm{Wm}^{-2}$. The skin temperature shows a small increase of $0.10 \pm 0.03 \mathrm{~K} / \mathrm{decade}$. This however has a very minor effect on the OLF trend (of less than $0.1 \mathrm{Wm}^{-2}$ ).

\section{Conclusions}

To summarize, our model calculations, which are based on ISCCP-D2 cloud climatologies, and temperature and humidity profile information from NCEP/NCAR reanalysis show that there has been an increase of OLR at TOA of $1.9 \pm 0.2 \mathrm{Wm}^{-2} /$ decade between $1984-2000$. This decrease is lower than the decrease displayed by the ERBE S-10N (WFOV NF edition 2) non-scanner OLR time-series, or by the results of Wielicki et al. (2002a, b). Analysis of the interannual and long-term variability of the various parameters determining the OLR at TOA, showed that the most important contribution to the observed trend comes from a decrease in high-level cloud cover over the period 1984-2000, followed by an apparent drying of the upper troposphere and a decrease of low-level cloudiness. Opposite but small trends are introduced by a decrease in low-level cloud top pressure, an apparent cooling of the lower stratosphere (at the $50 \mathrm{mbar}$ level) and a small decadal increase in mid-level cloud cover.

Acknowledgements. This research was funded by the European Commission (contract: EVK2-CT-2000-00055) under the Thematic Programme: Preserving the Ecosystem; Key Action 2: Global Change, Climate and Biodiversity. The ISCCP-D2 data were obtained from the NASA Langley Research Center (LaRC) Atmospheric Sciences Data Center (ASDC). The NCEP/NCAR Global Reanalysis Project data were obtained from the National Oceanic and Atmospheric Administration (NOAA) Cooperative Institute for Research in Environmental Sciences (CIRES) Climate Diagnostics Center, Boulder, Colorado, USA.

Edited by: Q. Fu

\section{References}

Allan, R. P. and Slingo, A.: Can current climate model forcings explain the spatial and temporal signatures of decadal OLR variations?, Geophys. Res. Lett., 29, 45-1-45-4, 2002.

Bates, J. J. and Jackson, D. L.: Trends in upper tropospheric humidity, Geophys. Res. Lett, 28, 1695-1698, 2001.

Chen, J., Carlson, B. E., Del Genio, A. D.: Evidence for Strengthening of the Tropical General Circulation in the 1990s, Science, 295, 838-841, 2002.

Chen, T., Zhang, Y., Rossow, W. B.: Sensitivity of atmospheric radiative heating profiles to variations of cloud layer overlap, J. Clim., 13, pp. 2941-2959, 2000.

Hatzianastassiou, N. and Vardavas, I.: Longwave radiation budget of the Southern Hemisphere using ISCCP C2 climatological data, J. Geophys. Res., 106, 17 785-17 798, 2001.

Hatzianastassiou, N., Croke, B., Kortsalioudakis, N., Vardavas, I., and Koutoulaki, K.: A model for the longwave radiation budget of the NH: Comparison with Earth Radiation Budget Experiment data, J. Geophys. Res., 104, 9489-9500, 1999.

IPCC, 2001: Climate Change: The scientific Basis, Contribution of Working Group I to the Third Assessment Report of the Intergovernmental Panel on Climate Change, edited by Houghton, J. T., Ding, Y., Griggs, D. J., Noguer, M., van der Linden, P. J., Dai, X., Maskell, K., and Johnson, C. A., Cambridge University Press, Cambridge, United Kingdom and New York, NY, USA, 2001.

Jacobowitz, H., Stowe, L. L., Ohring, G., Heidinger, A., Knapp, K., and Nalli, N. R.: The Advanced Very High Resolution Radiometer Pathfinder Atmosphere (PATMOS) Climate Dataset: A resource for Climate Research, Bull. Am. Meteor. Soc., 84, 785793, 2003.

Kistler, R., Kalnay, E., Collins, W., Saha, S., White, G., Woollen, J., Chelliah, M., Ebisuzaki, W., Kanamitsu, M., Kousky, V., van den Dool, H., Jenne, R., and Fiorino, M.: The NCEP-NCAR 50Year Reanalysis: Monthly Means CD-ROM and Documentation, Bull. Am. Meteor. Soc., 82, 247-268, 2001. 
Kley, D., Russell, J. M., and Phillips, C. (Eds.): SPARC Assessment of the upper tropospheric and stratospheric water vapour, WCRPNo. 113, WMO/TD-No. 1043, SPARC Report No. 2., 2000.

Pavlakis, K., Hatzidimitriou, D., Matsoukas, C., Drakakis, E., Hatzianastassiou, N., and Vardavas, I.: Ten-year global distribution of downwelling longwave radiation, Atmos. Chem. Phys., 4, 127-142, 2004, SRef-ID: 1680-7324/acp/2004-4-127.

Rossow, W. B. and Schiffer, R. A.: Advances in understanding clouds from ISCCP, Bull. Am. Meteor. Soc., 80, 2261-2288, 1999.

Schroeder, S. R. and McGuirk, J. P.: Widespread tropical atmospheric drying from 1979 to 1995, Geophys. Res. Lett, 25, 13011304, 1998.

Soden, B. J. and Schroeder, S. R.: Decadal variations in tropical water vapor, a comparison of observations and a model simulation, J. Climate, 13, 3337-3341, 2000.

Trenberth, K. E.: Changes in Tropical Clouds and Radiation, Science, 296, 2095, 2002.
Vardavas, I. and Carver, J. H.: Solar and terrestrial parameterizations for radiative convective models, Planet. Space Sci., 32, 1307-1325, 1984.

Wang, P. H., Minnis, P., Wielicki, B. A., Wong, T., and Vann, L. B.: Satellite observations of long-term changes in tropical cloud and outgoing longwave radiation from 1985 to 1998, Geophys. Res. Lett., 29, 37-1-37-4, 2002.

Wielicki, B. A., Wong, T., Allan, R. P., Slingo, A., Kiehl, J. T., Soden, B. J., Gordon, C. T., Miller, A. J., Yang, S., Randall, D. A., Robertson, F., Susskind, J., and Jacobowitz, H.: Evidence for large decadal variability in the tropical mean radiative energy budget, Science, 295, 841-844, 2002a.

Wielicki, B. A., Del Genio, A. D., Wong, T., Chen, J., Carlson, B. A., Allan, R. P., Robertson, F., Jacobowitz, H., Slingo, A., Randall, D. A., Kiehl, J. T., Soden, B. J., Gordon, C. T., Miller, A. J., Yang, S., and Susskind, J.: Changes in Tropical Clouds and Radiation, Response, Science, 296, 2095a, 2002b. 